\begin{tabular}{cc|c}
\hline Tar. Bil. Der. & Tarım Bilimleri Dergisi & Journal of Agricultural Sciences \\
& $\begin{array}{c}\text { Dergi web sayfası: } \\
\text { www.agri.ankara.edu.tr/dergi }\end{array}$ & Journal homepage: \\
& www.agri.ankara.edu.tr/journal
\end{tabular}

\title{
Çok Kriterli Değerlendirme ile Ankara Güvenç Havzası’nda Erozyon Risk Tahminlenmesi
}

\author{
İnci DEMİRAĞ TURAN ${ }^{a}$, Orhan DENGİZ \\ ${ }^{a}$ Ondokuz Mayıs Üniversitesi, Fen Edebiyat Fakültesi, Coğrafya Bölümü, Samsun, TÜRKiYE \\ ${ }^{b}$ Ondokuz Mayıs Üniversitesi, Ziraat Fakültesi, Toprak Bilimi ve Bitki Besleme Bölümü, Samsun, TÜRKiYE
}

\section{ESER BILGISII}

Araștırma Makalesi DOI: 10.15832/ankutbd.447600

Sorumlu Yazar: İnci DEMIRAĞ TURAN, E-posta: dmrginci@gmail.com, Tel: +90 (542) 8041527

Geliş Tarihi: 18 Haziran 2014, Düzeltmelerin Gelişi: 02 Aralık 2015, Kabul: 03 Aralık 2015

\begin{abstract}
ÖZET
Bu çalışmanın amacı, Ankara Güvenç Havzası'nın coğrafi bilgi sistemi (CBS), uzaktan algılama (UA) ve istatistik yaklaşımlar kullanarak çok kriterli değerlendirme ile erozyon risk sınıflarının belirlenmesi ve haritalanmasıdır. Çalışma havzası yaklaşık $17.3 \mathrm{~km}^{2}$ 'lik bir alanı kapsamaktadır. Erozyon risk sınıflarının belirlenmesi amacıyla havzada toprak erozyonunun meydana gelmesinde etkili olan yedi adet parametre (bünye, toprak derinliği, yağış, arazi kullanımı, yükseklik, eğim ve bitki örtüsü) ve bu parametrelere ait alt kriterler dikkate alınmıştır. Parametrelere ait veriler için çalışma alanının 1:25000 ölçekli sayısal temel toprak haritası ve topografik harita kullanılmıştır. Arazi kullanımı-arazi örtüsünün ve bitki örtüsünün belirlenmesi amacıyla Landsat 7 uydu görüntüsünden yararlanılmıştır. Parametrelerin önceliklerinin belirlenmesinde analitik hiyerarşik süreç (AHS) tekniği, alt kriterlerin önceliklerinin belirlenmesinde ise Z-Skor istatistik analizi tekniğinden faydalanılmıştır. Nihai olarak ise dört sınıftan oluşan erozyon duyarlılık sınıflarının belirlenmesinde doğrusal kombinasyon tekniği kullanılmıştır. Elde edilen analiz sonuçlarına göre havzanın \% 45.9 'unun çok şiddetli erozyon riskini taşıdı̆̆ belirlenmiştir.
\end{abstract}

Anahtar Kelimeler: Analitik hiyerarşik süreç; Doğrusal kombinasyon tekniği; Erozyon risk belirleme; Z-Skor

\section{Erosion Risk Prediction Using Multi-Criteria Assessment in Ankara Güvenç Basin}

\section{ARTICLE INFO}

Research Article

Correponding Author: İnci DEMIRAĞ TURAN, E-mail: dmrginci@gmail.com, Tel: +90 (542) 8041527

Received: 18 June 2014, Received in Revised Form: 02 December 2015, Accepted: 03 December 2015

\begin{abstract}
The aim of this study is to determine erosion risk classes and to generate their map in Ankara Güvenç Basin using geographic information system (GIS), remote sensing (RS) and statistical approaches with method of multi-criteria decision-making. Basin covers about $17.3 \mathrm{~km}^{2}$. In order to determine erosion risk classes, seven criteria (texture, soil depth, precipitation, land use, elevation, slope and vegetation) that influence the occurrence of soil erosion, and
\end{abstract}


sub-criteria of that seven criteria were taken into consideration. 1:25000 scale digital soil map and topographic map were used. In addition to that, Landsat 7 satellite images were used to generate the land use and vegetation cover map. Analytical hierarchy process (AHP) technique was used to determine the priorities of the each criteria while, the Z-score statistical analysis technique was used to determine the priorities of the sub-criteria. Finally, linear combination technique was used to determine classes of erosion risk. According to the obtained results, $45.9 \%$ of the basin area was identified as under high erosion risk.

Keywords: Analytical hierarchy process; Determining erosion risk; Linear combination technique; Z-Score

\section{Giriş}

Toprak erozyonu bugün dünyada tarımı, doğal kaynakları ve çevreyi tehdit eden en önemli problemlerden birisidir. Aslında erozyon, doğal jeomorfolojik bir süreçtir. Ancak insan etkisi sonucu erozyon, hızlandırılmış hale dönüşmüştür. Hızlandırılmış erozyon da çevreye olan baskıyı artırarak, önemli bir çevresel problem haline gelmiştir. Eğer toprak erozyonunun mekânsal ve zamansal büyüklüğü bilinirse, yönetimsel uygulamalar bu problemi en aza indirmek için etkili bir şekilde gerçekleştirilebilir. Herhangi bir havzada erozyon süreçleri ve erozyon oranlarını belirlemek amaciyla toprak erozyon modelleri geliştirilmekte ve uygulanmaktadır. Toprak erozyonu tahmini ve değerlendirilmesi ile ilgili 1930'dan beri pek çok çalışma yapılmış ve birçok model geliştirilmiştir (Lal 2001). En yaygın olan modellerden bazıları evrensel toprak kayb1 eşitliği (USLE) (Wischmeier \& Smith 1978) ve revize edilmiş toprak kaybı eşitliği (RUSLE) (Renard et al 1991)'dir. Erozyon verimlilik etkisi hesaplaması (EPIC) (Williams et al 1990), Avrupa toprak erozyon modeli (EUROSEM) (Morgan et al 1992) ve su erozyonu tahmin projesi (WEPP) (Flanagan \& Nearing 1995) gibi birçok model, toprak kaybı tahmininde kullanılmasinın yanı sıra alanın erozyona karşı duyarlılık durumlarını belirlemek amaciyla da CORINE (1992), ICONA (1997), LEAM (Manrique 1988) gibi birçok erozyon risk değerlendirme modelleri de geliştirilmiştir. Bütün bu yöntemlerle ne kadar toprak kaybının olabileceği veya herhangi bir yönetim senaryosu altında erozyon riskine dair çıkarımlar yapılabilmesi söz konusudur. Arazi bozulmasını azaltmak ve toprak kaynaklarının sürdürülebilir bir şekilde kullanılmasını sağlamak amaciyla toprak koruma tedbirlerinin alınması gerekmektedir. Tedbirlerin alınması için öncelikle erozyon alanının erozyon risk dağılım haritalarının yapılması gerekir. Böylelikle toprak erozyonuna karşı gerekli yönetim planlamaları ve çalışmaları yapılabilmektedir.

Toprak erozyonunu hesaplamak veya risk dağılımlarının belirlemek için iklim, bitki örtüsü, arazi kullanımı, fiziki coğrafya özellikleri gibi çeşitli parametreler ele alınmıştır. Zhang et al (2013) tarafından yapılan çalışmada coğrafi bilgi sistemleri (CBS) ve uzaktan algilama (UA) teknolojileri kullanılarak yağış, toprak, topografya ve vejetasyon parametrelerinin erozyon üzerindeki etkileri değerlendirilmiştir. Wu \& Wang (2007) analitik hiyerarşik süreç (AHS), uzaktan algılama ve coğrafi bilgi sistemlerini bir arada değerlendirmişler ve erozyona etki eden toprak tipi, yağmur yoğunluğu, arazi şekli, derin vadi yoğunluğu, arazi eğimi, bitki örtüsü, maden sahası, su ve toprak koruma seviyesi ve arazi kullanımı faktörlerini ele almışlardır. Aynı çalışmada toprak erozyonu risk derecesinin tematik katmanlarının CBS ile yapıldığı ve her tematik katmanın ağırlığına ise AHS ile karar verildiği belirtilmiştir.

$\mathrm{Bu}$ çalışma ile Ankara Güvenç Havzası içerisinde dağılım gösteren arazilerin erozyon risk durumlarının belirlenmesi ve dağılım haritalarının oluşturulması amaçlanmıştır. $\mathrm{Bu}$ doğrultuda, toprak erozyonunu etkileyen toprak derinliği, toprak bünyesi, bitki örtüsü indeksi (NDVI), eğim, yağış, yükseklik ve arazi kullanımından oluşan yedi faktör ve bunlara ait alt faktörler 
dikkate alınmıştır. Faktörler arasındaki ilişkilerin değerlendirmesinde çok kriterli yaklaşımlarından olan AHS uygulanmış ve alt faktörlerde ise Z-Skor analizi yapılarak kriterler aynı ölçeğe konulup artık birlikte toplanabilir, yani kombine edilebilir hale getirilmiştir. Böylece bu teknik ile erozyon riski değerlendirmesi çalışmalarına yönelik yeni bir yaklaşım geliştirilmiştir.

\section{Materyal ve Yöntem}

\section{1. Çalışma alanı}

Çalışma alanı Güvenç Göleti'ne ait su toplama havzasıdır. Güvenç Göleti Ankara-YenimahalleGüvenç Köyü’nde yer almaktadır. Çalışma alanının lokasyon haritası Şekil 1 olarak sunulmuştur. Havza yaklaşık $17.3 \mathrm{~km}^{2}$ alana sahiptir (Şekil 1).

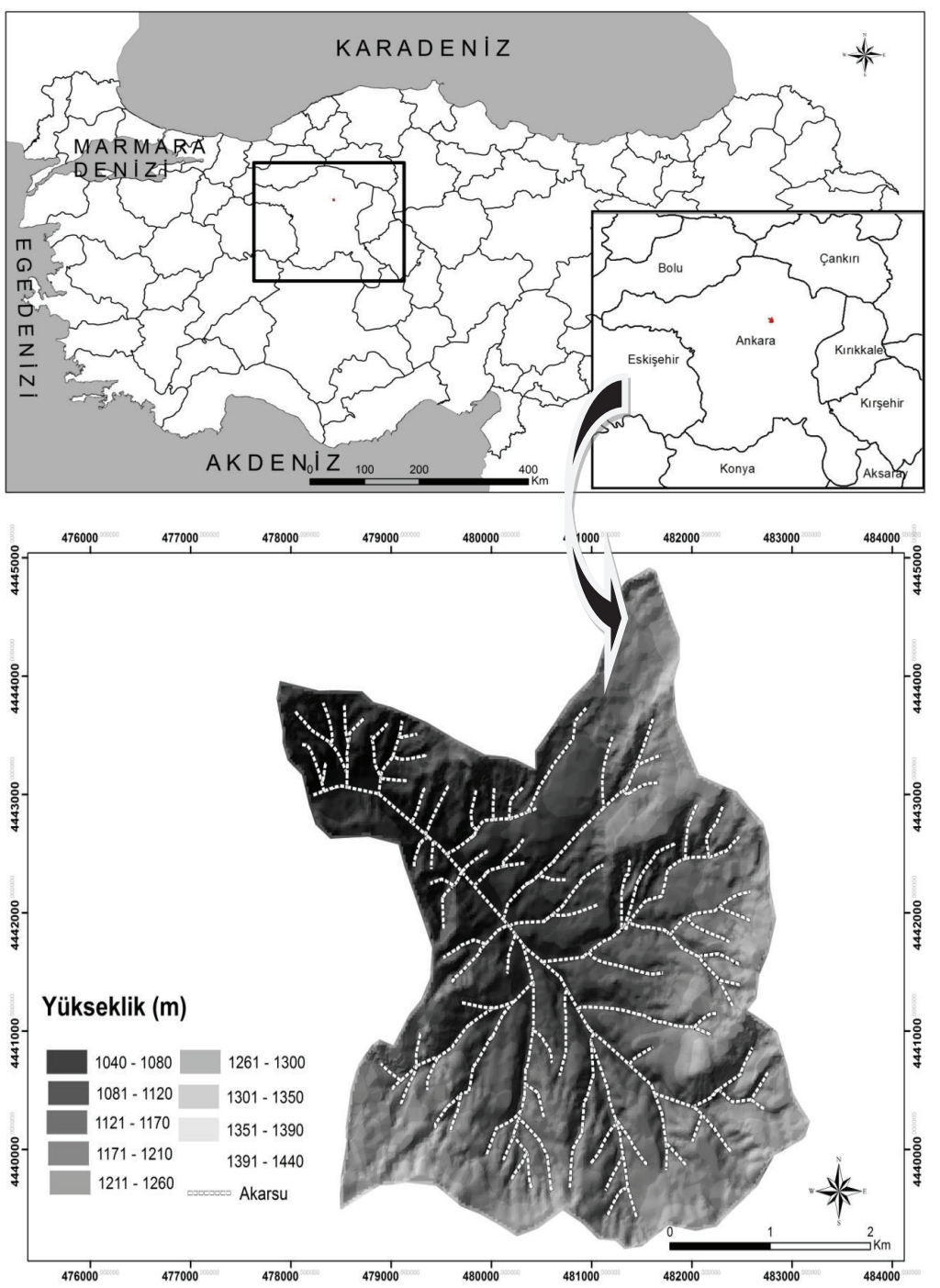

Şekil 1- Çalışma alanının lokasyon haritası

Figure 1-Location map of the study area 
Güvenç Havzası yazları sıcak ve kurak, kışları soğuk ve yağışlıdır. Ankara Meteoroloji Müdürlüğü verilerine göre (1975-2013) yıllık ortalama yağış $399.5 \mathrm{~mm}$, uzun yıllar ortalama sıcaklığ ${ }^{\circ} \mathrm{C}$ 'dir (MGM 2013). Havzanın deniz seviyesinden olan yükseltisi $1040 \mathrm{~m}$ ile $1440 \mathrm{~m}$ arasındadır. Özellikle Havza alanının yaklaşık \% 50'si 1200$1350 \mathrm{~m}$ yükseklik arasında yer almaktadır. Ayrıca alanın yaklaşı $\% 46$ 'sının $11^{\circ}-30^{\circ}$ arasında eğim değerlerine sahip olduğu belirlenmiştir.

Havzanın batı ve orta kesiminde Paleosen yaşlı kil ve kireçtaşı ara katmanları ile Sarıbeyler formasyonu dağılım göstermiştir. Bu birimler az geçirimli özelliğe sahiptir. Havzanın yukarı su toplama alanında kireç taşı ile marn kayaçlarından oluşan tabakalar bulunmaktadır. Buralarda yeraltı suyu verimliliğinin oldukça zayıf olduğu görülmüştür (DSİ 1969).

Havzanın güneybatısı ile kuzeydoğusu Orhaniye formasyonu ve Sarıbeyler formasyonu üzerinde yer almıştır. Orhaniye formasyonu orta derecede verimliliğe sahiptir. Havzanın güneydoğusunda siltli kumtaşı ile Dikmendere formasyonu yüzeylenmiştir. Formasyonların birbirlerine temas ettiği yerlerde yer yer su kaynakları bulunmaktadır (MTA 1994).

\subsection{Yöntemler}

Havzanın erozyon risk dağılımlarının belirlenmesinde, havzada öncelikli olarak erozyona etki edebilecek parametreler tanımlanmış ve alana ait detaylı toprak haritasında yer alan her bir haritalama ünitesi için erozyon duyarlılığının oranları hesaplanmıştır. Erozyon risk haritalarının oluşturulmasına yönelik çalışmalarda da çok kriterli karar verme yöntemi uygulanmış ve uygulanmaya da devam etmektedir. Buna yönelik birçok teknik olmasına karşın bu çalışmada çok kriterli erozyon risk değerlendirmesi tekniği olarak doğrusal kombinasyon tekniği kullanılmıştır (Patrono 1998).

Doğrusal kombinasyon tekniğinde, erozyona etki eden kriterlerin her birine bir ağırlık değeri aktarılmıştır. Bu ağırlık değerleri, kriterlerin göreceli önemine göre belirlenmiştir. Sonrasında bu kriterler alt kriterlere ayrılmış ve bu alt kriterler kendi içinde ayrı bir sayısal değerlendirmeye tabi tutularak alt kriter puanları saptanmıştır. Daha sonra bu alt kriter puanları, ait olduğu kriterin ağırlık değeri ile çarpılmıştır (Dengiz \& Sarıoğlu 2013). Çalışmada, alt kriterlere ait değerler Z-Skor yöntemiyle, ait olduğu kriterin ağırlık değeri ise AHS yöntemi ile belirlenmiştir.

Böylece kriterler aynı ölçeğe konularak birlikte toplanabilir, yani kombine edilebilir hale getirilmiştir. $\mathrm{Bu}$ teknikteki erozyon riski değerlendirmesi yaklaşımına ait matematiksel ifade Eşitlik 1'de verilmiş̧tir.

$$
S=\sum_{i=1}^{n}\left(W_{i} \cdot X_{i}\right)
$$

Burada; $S$, erozyon risk puan1; $W_{i}$, i parametrenin ağırlık değeri; $X_{i}$, i parametresine ait $Z$-Skor alt kriter puanı; $n$, ele alınan parametrelerin toplam sayısıdır.

Ele alınan kriterler alt faktörlere ayrılarak 1 ile 4 arasında ağırlık değerleri verilmiştir. Erozyon risk sinıflamasına yönelik modelde kullanılan parametreler ve alt faktörlere ait ağırlık puanları Çizelge 1'de belirtilmiştir. Alt faktör, erozyonun risk ihtimalinin yüksek olması durumunda 1, erozyonun risk durumu az ise 4 değerini almıştır. 1 ile 4 arasındaki değerler ise erozyonun risk derecesine göre değişmektedir (Çizelge 1).

Erozyon risk değerlendirmesinde doğru ve karşılaştırılabilir sonuçlar elde etmek zordur. $\mathrm{Bu}$ nedenle toprak erozyon risk değerlendirmesinde belirlenen alt faktörler, CBS ile sayisal bir model olan Z-Skor birleştirilmiştir. Z-Skor'da dönüşüm kurallarında özel bir uygulama yapılmaktadır. Değişken alt parametreler için Z-Skor metodu kullanılarak standartlaştırma yapılmıştır. Z-Skor değeri bazen standart puanlar şeklinde de ifade edilmektedir.

Standartlaştırma her bir alt parametreden, ortalama farkının alınması ve elde edilen değerin standart sapmaya bölünmesi ile belirlenmiştir. Böylece, Z-Skor ham verileri standart hale dönüşmüş ve birim farklılıklarını ortadan kaldırmıştır. Z-Skor hesaplanması Eşitlik 2'de verilmiştir. 
Çizelge 1- Erozyon risk sınıflamasına yönelik modelde kullanılan parametreler ve alt faktörlere ait ağırlık puanları

Table 1- Weighted values for parameters and sub factors which are used in model for determination of erosion risk class

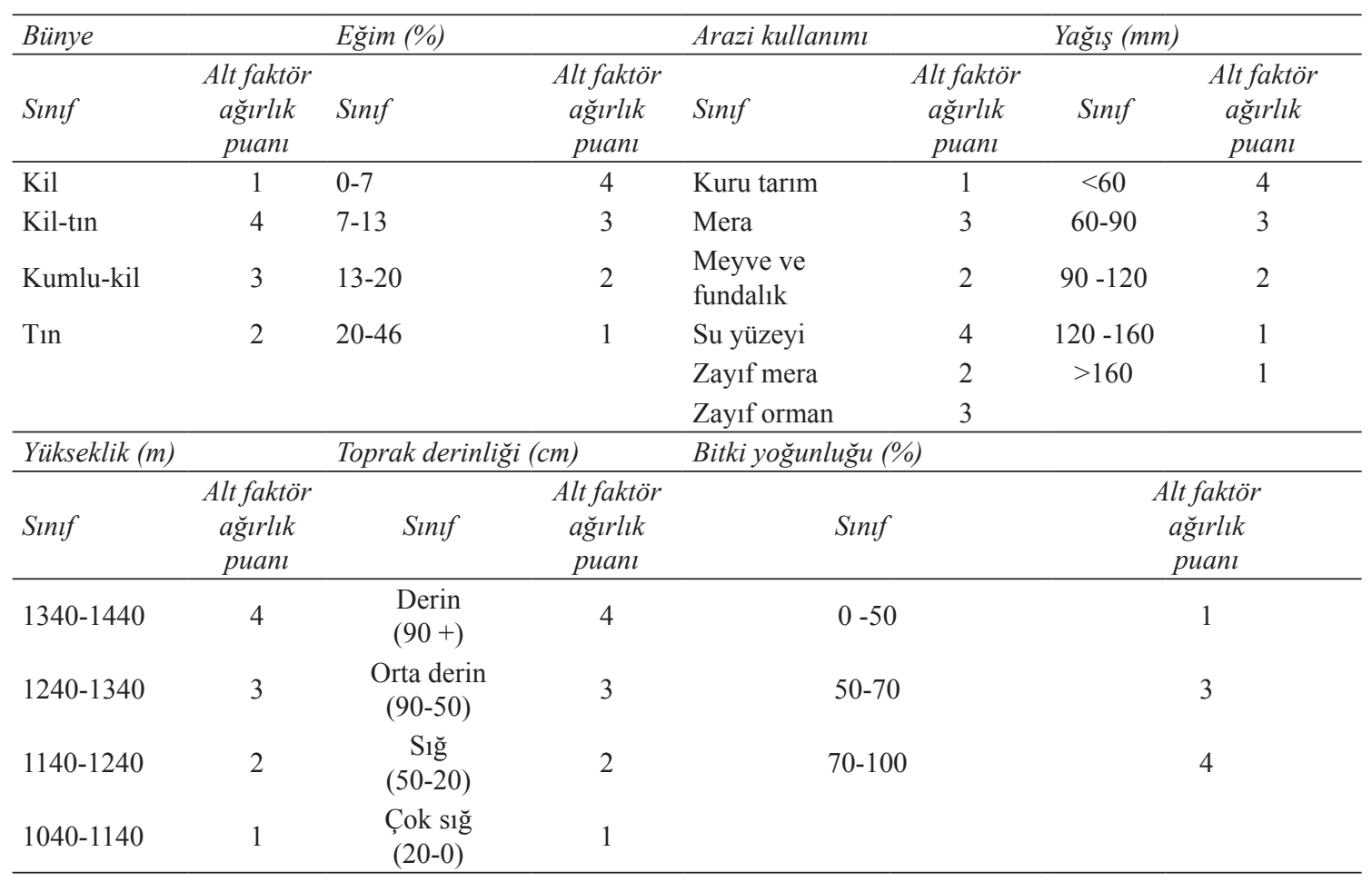

$$
Z i j=\frac{x i j-\mu i}{\sigma i}
$$

Burada; Zij, faktörlerin skor değeri; xij, parametrelerin ağırlık değerleri; $\mu \mathrm{ijj}$ ağırlık değerlerinin ortalaması; $\sigma \mathrm{i}$, ağırlık değerlerinin standart sapmasidır.

Ana kriterlerin her birine ait ağırlık puanlarının belirlenmesinde değerlendirmeye alınan kriterlerin birbirlerine göre önemi dikkate alınarak Saaty (1980) tarafından geliştirilen AHS tekniği kullanılmıştır. $\mathrm{Bu}$ teknik ile parametreler ikili karşılaştırılıp öncelik değeri belirlenmiştir. Ayrıca bu teknik karar alternatifinin seçilmesinde, hem nicel hem de nitel faktörlerin dikkate alınmasına imkân vermektedir. İkili karşılaştırmalara dayalı göreceli önceliklendirme ölçeği Çizelge 2'de verilmiştir (Saaty 1980).
Çalışmada değerlendirmeye alınan kriterlerin ağırlık puanları AHS tekniği ile belirlenirken aşağıdaki adımlar izlenmiştir.

Birinci adımda kriterlerin etki durumu göz önünde bulundurularak ikili karşılaştırmaların yapıldığı matrisler oluşturulmuştur (Eşitlik 3).

$$
A=\left[\begin{array}{lll}
a 11 & a 12 \ldots & a 1 n \\
a 21 & a 22 \ldots & a 2 n \\
a n 1 & a n 2 \ldots & a n n
\end{array}\right]
$$

Burada; $A$, karşılaştırma matrisi; $\mathrm{a}_{\mathrm{ij}}$, hiyerarşinin bir üst düzeydeki elemanına önemi $(i, j=1,2, \ldots, n)$; İkili karşılaştırma matrisinin özellikleri, $\mathrm{a}_{\mathrm{ji}}=1 / \mathrm{a}_{\mathrm{ij}}$, aij $>0(i, j=1,2, \ldots, n)$; karşılaştırmalar matrisinin tutarlılığ $1, a_{i k}=a_{j i} a_{j k}(i, j, k=1,2, \ldots, n)$. 


\section{Çizelge 2- AHS tekniğinde tercihler için kullanılan ikili karşılaştırmalar ölçeği (Saaty 1980)}

Table 2- The pairwise comparisons scales used for the preferences in the AHP (Saaty 1980)

\begin{tabular}{|c|c|c|}
\hline Sözel tercih hükmü & Açılama & Dĕger \\
\hline Eşit tercih edilme & İki faaliyet amaca eşit düzeyde katkıda bulunur & 1 \\
\hline Kismen tercih edilme & Tecrübe ve yargı bir faaliyeti diğerine göre kısmen tercih ettiriyor & 3 \\
\hline Oldukça tercih edilme & Tecrübe ve yargı bir faaliyeti diğerine göre oldukça tercih ettiriyor & 5 \\
\hline Kuvvetle tercih edilme & $\begin{array}{l}\text { Bir faaliyet değerine göre kuvvetle tercih ediliyor ve baskınlığı uygulamada } \\
\text { rahatlıkla görünüyor }\end{array}$ & 7 \\
\hline Kesinlikle tercih edilme & $\begin{array}{l}\text { Bir faaliyetin değerine göre tercih edilmesine ilişkin kanıtlar çok büyük bir } \\
\text { güvenirliğe sahip }\end{array}$ & 9 \\
\hline Orta değerler & Uzlaşma gerektiğinde kullanılmak üzere iki ardışık yarg1 arasına düşen değerler & $2,4,6,8$ \\
\hline Ters (karşıt) değerler & $\begin{array}{l}\text { Bir eleman başka bir elemanla karşılaştırıldığında yukarıdaki değerlerden } \\
\text { birisi atanır. Bunlardan ikinci eleman birinci eleman ile karşılaştırıldığında ters } \\
\text { değere sahip olur }\end{array}$ & \\
\hline
\end{tabular}

İkili karşılaştırma hükümleri kesin olarak tutarlı ise, A ikili karşılaştırmalar matrisinin girdileri hata içermez ve Eşitlik 4' te olduğu gibi ifade edilir.

$\mathrm{a}_{\mathrm{ij}}=\frac{W i}{W j}$

Burada; $W_{i}$, A ikili karşılaştırmalar matrisi vasıtasıyla hesaplanmış olan i elemanına ilişkin öncelik değer; $\mathrm{W}_{\mathrm{j}}$, A ikili karşılaştırmalar matrisi vasıtasıyla hesaplanmış olan j elemanına ilişkin öncelik değerdir.

Eşitlik 4'ten faydalanılarak Eşitlik 5 oluşturulmuştur.

$a_{i k} a_{k j}=\frac{W_{i}}{W_{k}} \cdot \frac{W_{k}}{W_{j}}=\frac{W_{i}}{W_{j}}=a_{i j} \quad(\mathrm{i}, \mathrm{j}, \mathrm{k}=1,2, \ldots, \mathrm{n})$

Burada; İkili karşılaştırmalar matrisinin köşegen elemanları değeri 1 olup $\left(a_{i i}=1(i, j, k=1,2, \ldots, n)\right)$ şeklinde ifade edilmiştir.

Matrisin oluşturulmasından sonra karşılaştırılan parametrelerin her birinin önceliğinin hesaplanmasında ilk önce ikili karşılaştırmalar matrisinin her sütunundaki değerler toplanmıştır. Daha sonra ikili karşılaştırmalar matrisindeki her bir eleman, bulunduğu sütunun toplam değerine bölünmüştür. Bunun sonucunda normalize edilmiş ikili karşılaştırmalar matrisi elde edilmiştir. Son aşamada da normalize edilmiş ikili karşılaştırmalar matrisinin her bir satırındaki elemanların aritmetik ortalaması hesap edilmiştir.
Yöntemin son aşamasında, elde edilen özvektörün tutarlılık kontrolünün yapılması işlemi gerçekleştirilmiştir. İkili karşılaştırmalar matrisi (A), öncelik vektörü (W) ile çarpılarak yeni bir vektör elde edilmiştir. Yeni vektörün her bir elemanını öncelik vektöründe buna karşılık gelen değere bölerek ikinci bir yeni vektör hesaplanmıştır. Son vektör değerlerinin aritmetik ortalaması alınarak maksimum özdeğere $\left(\lambda_{\max }\right)$ ulaşılmıştır. Kumar \& Ganesh (1996) maksimum özdeğerin ikili karşılaştırmalar matrisindeki elemanların sayısına (n) yakın oldukça sonucun da o kadar tutarlı olacağını belirtmişlerdir.

Tutarlılık oranı Eşitlik 6'da verilen tutarlılık indeksi (TI)'ne göre hesaplanmıştır.

$\mathrm{T} \dot{\mathrm{I}}=\frac{\lambda \max -\mathrm{n}}{n-1}$

Ayrıca tutarlılık oranını hesaplayabilmek için rastgele (tesadüfi) indeksi değeri belirlenmiştir. AHS tekniğindeki tutarlılık oranının hesaplanmasında kullanılan (Eşitlik 7) ve matris boyutlarına göre değişen rastgele indeks değerleri Çizelge 3 'te verilmiştir.

$T O=\frac{T \dot{\mathrm{I}}}{R \dot{\mathrm{I}}}$

Tutarlılık kontrolü, yargılarda olabilecek hataların tanımlanmasına olanak sağlamıştır. Yöntemin geçerli olması için Saaty (1980) tutarlılık 
Çizelge 3- AHS tekniğindeki tutarlılık oranının hesaplanmasında kullanılan ve matris boyutlarına göre değişen rastgele indeks değerleri (Saaty 1980)

Table 3-Random index used in measured consistency ratio and which varies functionally with size of matrix in the AHP (Saaty 1980)

\begin{tabular}{cccccccccccccccc}
\hline $\mathrm{n}$ & 1 & 2 & 3 & 4 & 5 & 6 & 7 & 8 & 9 & 10 & 11 & 12 & 13 & 14 & 15 \\
\hline $\mathrm{RI}$ & 0.00 & 0.00 & 0.58 & 0.90 & 1.12 & 1.24 & 1.32 & 1.41 & 1.45 & 1.49 & 1.51 & 1.48 & 1.56 & 1.57 & 1.59 \\
\hline
\end{tabular}

oranının 0.10 (\% 10) veya daha küçük olması gerektiğini, eğer bu oran 0.10 'dan büyük ise ikili karşılaştırma matrislerinin yeniden oluşturulması gerektiğini belirtmiştir.

Her bir haritalama ünitesi için doğrusal kombinasyon tekniği ile hesaplanan değerler Çizelge 4'e göre sinıflandırılarak alanın erozyon duyarlılık haritası oluşturulmuştur.

\section{Çizelge 4- Erozyon duyarlılık sınıfları ve sınıflara} ait değerleri

Table 4- The casses of erosion sensitivity and values of the classes

\begin{tabular}{lll}
\hline Tanımlama & Sinıf & Dĕ̌er \\
\hline Az veya hiç yok & E1 & $>0.2567$ \\
Orta & E2 & $0.2566-0.1092$ \\
Şiddetli & E3 & $0.1091-0.000$ \\
Çok şiddetli & E4 & $<0.0000$ \\
\hline
\end{tabular}

Yapılan erozyon riskini değerlendirme çalışmasında belirleyici olabilecek toplam yedi parametre dikkate alınmıştır. $\mathrm{Bu}$ parametrelerin dikkate alınmasında özellikle suyun toprak içerisinde depolanması, yüzey akışı ve toprak taşınımına etkisi olan arazi ve toprak özellikleri etkili olmuştur. Ayrıca bu parametreler, yaygin olarak CORINE, ICONA, LEAM, WEPP, EUROSEM, EPIC gibi birçok farklı modelsel çalışma içerisinde de kullanılmışlardır. Araştırmada kullanılan parametreler sırasıyla eğim, bünye, arazi kullanımı, yağış, toprak derinliği, yükseklik ve bitki örtüsü yüzey kaplama oranı şeklindedir. Kriterlere ait veriler için çalışma alanının 1:25000 ölçekli sayısal temel toprak haritası ve ANKARA H29d2 paftası içerisine giren 1:25000 ölçekli topografik haritası kullanılmıştır. Topografik haritaların sayısallaştırılmasının yanı sıra katman sorgulama ve analiz işlemlerinde ArcGIS 9.3v coğrafi bilgi sistemi programından yararlanılmıştır. Arazi kullanımı ve bitki örtüsü yoğunluğunun belirlenmesi amaciyla Landsat 7 uydu görüntüsü, yağış erozyon faktörünün belirlenmesinde fournier indeksi kullanılmıştır (CORINE 1992). Fournier indeksinin belirlenmesinde 1970-2013 yıllarına ait meteorolojik verilerden yararlanılmıştır (MGM 2013). İndeksin hesaplanmasında Eşitlik 8 kullanılmıştır.

$$
F I=\sum_{i=1}^{12} \frac{P i^{2}}{\bar{P}}
$$

Burada; $P i$, i ayındaki toplam yağış $(\mathrm{mm}) ; \bar{P}$, yıllık ortalama yağış miktarı $(\mathrm{mm})$ 'dır.

Erozyon sürecinde önemli bir faktör olan eğim ve bünye alt sınıflarının belirlenmesinde Van Zuidam (1986) tarafindan belirtilen siniflandirmadan yararlanılmış ve eğim, alana ait sayısal yükselti modelinden üretilmiştir. Toprak derinlik sınıfları ise TÜGEM (2008) dikkate alınarak hazırlanmıştır. Toprak derinliği ve tekstür verileri Dengiz \& Başkan (2005) tarafından yapılmış çalışmadan elde edilmiştir. Bitki örtüsü yoğunluk sınıflamasında ICONA (1997)'dan yararlanılmıştır. Yükseklik parametresinin ise bireysel olarak değil de ikili karşılaştırma matrisinde eğimin derecesi ile birlikte ele alındığında, erozyona olan etkisi bakımından özellikle suyun kinetik enerjisindeki artış veya azalışa neden olması dolaysıyla da toprağı taşıma kapasitesi üzerine etki etmesi yönünden önemli faktör olduğu düşünülmüsşür. Bu nedenle havzanın kendine ait yükselti değişkenlikleri dört sınıfa ayrılmıştır. 


\section{Bulgular ve Tartışma}

Analitik hiyerarşik süreç tekniği, çok kriterli problemlerin çözülmesinde kullanılan güçlü bir araçtır. Ayrıca ağırlıkların belirlenmesinde faydalanılan diğer yöntemlerle karşılaştırıldığında tutarsızlığın ölçümüne olanak sağlaması bakımından önemlidir. Karar verme süreçlerinde AHS'nin tek başına kullanımı, incelemeye konu olan alandaki mekânsal farklılıkları yansıtamadığı için yetersiz kalmaktadır (Carver 1991; Malczewski 1996). $\mathrm{Bu}$ eksiklik CBS ile giderilmiş böylece, sonuçlar haritalanma olanağı bulmuştur. Yapılan bu çalışmada da belirtilen hususlar göz önünde tutularak her parametrenin alt parametreleri belirlenmiş, Z-Skor ve CBS analizleri ile değerlendirmeleri yapılmıştır.

Çalışma alanında toprak erozyonuna neden olabilecek öncelikli parametreler dikkate alınarak CBS ile UA teknikleri yardımıyla matematiksel (AHS ve DKT) ve istatistiksel (Z-Skor) yaklaşımlar kullanılarak havzanın erozyon risk durumu değerlendirilmiştir. Araştırma sahasında Landsat 7 uydu görüntüleri yardımıyla bitki örtüsü yoğunluğu ve arazi kullanım desenine yönelik parametreler belirlenmiştir. Havzanın büyük bir kısmını kuru tarım (\% 45) ve mera (\% 35) oluştururken, geri kalan kısmını ise fundalık, zayıf orman ve çıplak kaya oluşturmaktadır (Şekil 2). Ayrıca \% 74'ünün bitki örtüsü yoğunluğu bakımından \% 0-50 arasında olduğu belirlenmiştir.

Çalışma alanında toplam alanın \% 50'sinde eğimin \% 10'dan az, \% 10'unda ise eğimin \% 20'den fazla olduğu belirlenmiştir (Şekil 3).

Toplam alanın yaklaşı \% 63 'ünde ise yükseltinin $1120 \mathrm{~m}$ ile $1300 \mathrm{~m}$ arasında olduğu belirlenmiştir.

Toprak derinlik dağılım haritası Şekil 4'te verilmiştir. Buna göre toplam alanın yaklaşık

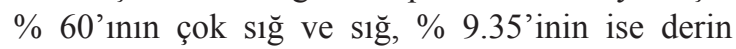
olduğu belirlenmiştir.

Havzanın toprak bünyesi dağılımında ise toplam alanın yaklaşık \% 58'inin killi-tın ve kumlu-kil, \% 36'sının ise killi tekstüre sahip topraklar olduğu haritalandırılmıştır (Şekil 5). Kumlu-kil ve killitın bünyeli topraklar, kil bünyeli topraklara göre erozyona daha fazla duyarlıdır.

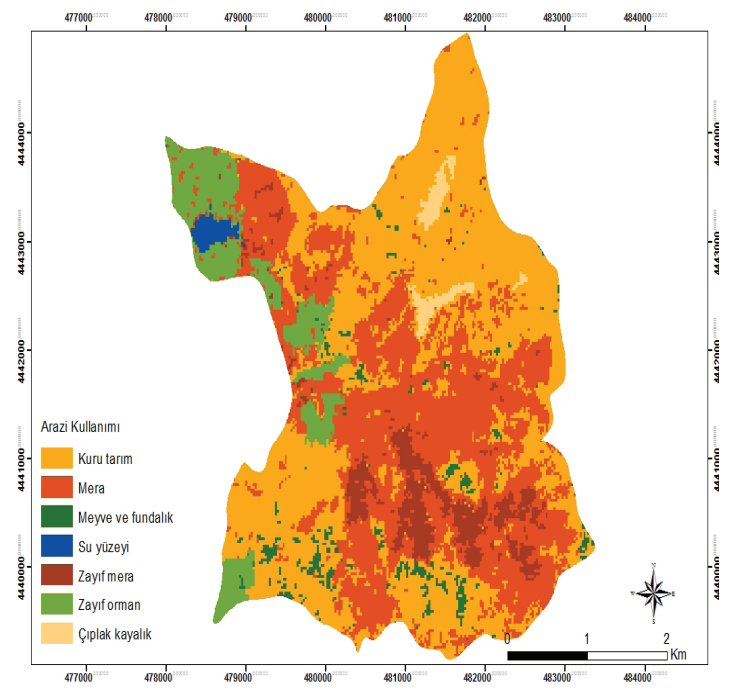

Şekil 2- Çalışma alanının arazi kullanım haritası

Figure 2-Land use map of the study area

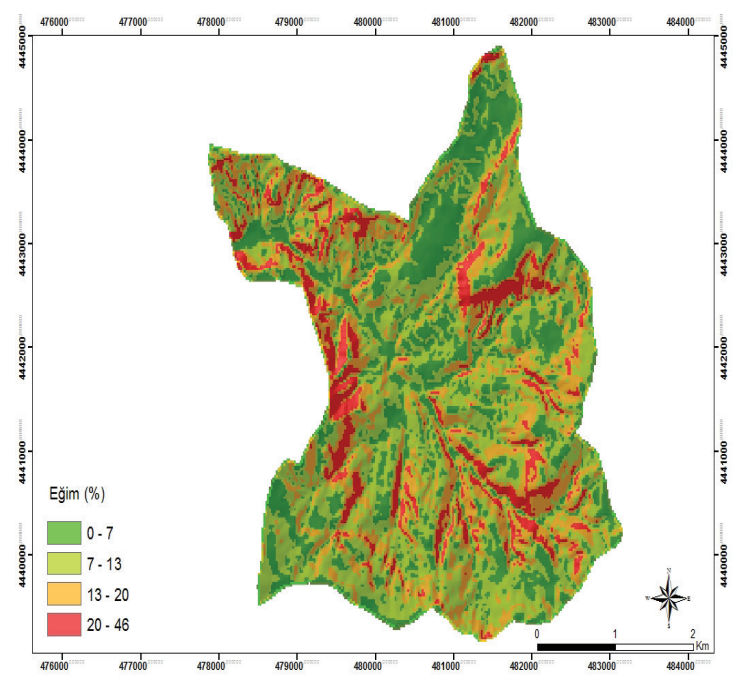

Şekil 3- Çalışma alanının eğim haritası

Figure 3-Slope map of the study area

Havzanın uzun yıllara ait yağış değerleri dikkate alındığında FI değeri 37.68 olarak bulunmuştur. Bu değer FI sinıflamasina göre 1. sinıfa girmektedir. Ayrıca alt faktör ağırlık puanı ise 4 olarak belirlenmiştir (Çizelge 2). 


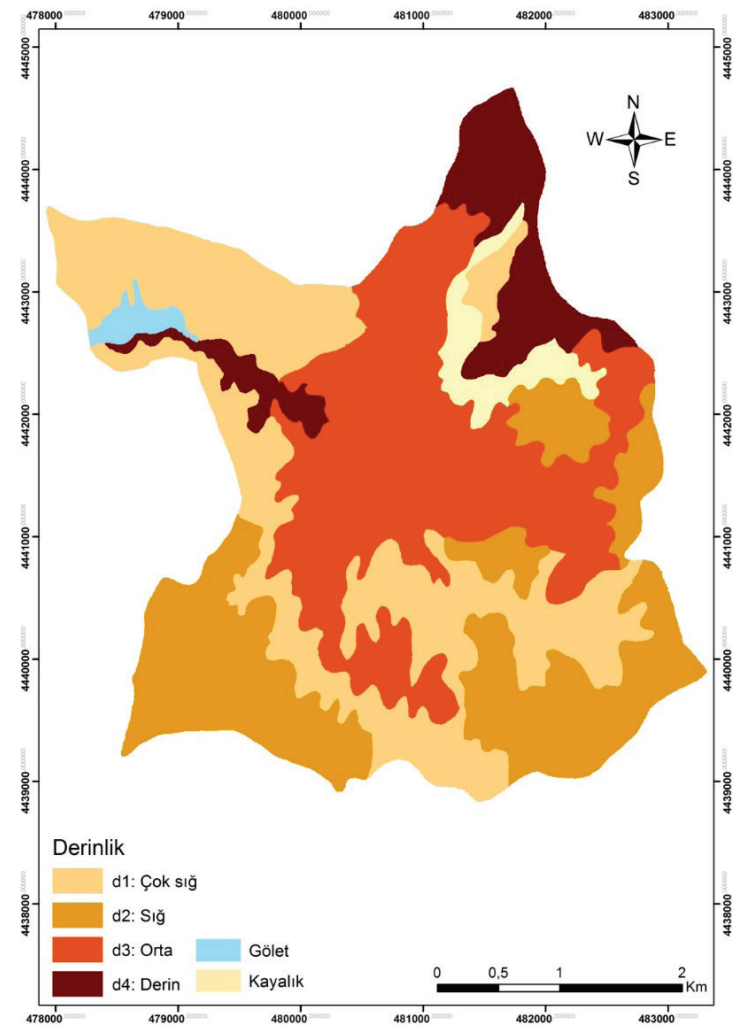

Şekil 4- Çalışma alanının toprak derinlik haritası

Figure 4- Soil depth map of the study area

Tüm parametrelerin alt parametreleri belirlenirken Z-Skor analizi yönteminden yararlanılmış ve elde edilen sonuçlar Çizelge 5'te verilmiştir.

Çalışma alanının erozyon riskine yönelik duyarlılık sınıflarının belirlenmesinde seçilen kriterler için yapılan ikili karşılaştırmalara dayalı olarak elde edilen ağırlık değerleri Çizelge 6'da sunulmuştur.

Çizelge 6'dan görüleceği üzere, 0.358 ağırlık değeri ile bu uygunluk kriterlerinden eğim kriteri en yüksek ağırlığa sahip kriter olarak ortaya çıkmıştır. $\mathrm{Bu}$ kriteri sırasıyla arazi kullanımı (0.179), toprak bünyesi (0.156), yağış faktörü (0.116), yükseklik (0.092), toprak derinliği (0.060) ile bitki örtüsü kriterlerinin (0.033) izlediği belirlenmiştir. $\mathrm{Bu}$

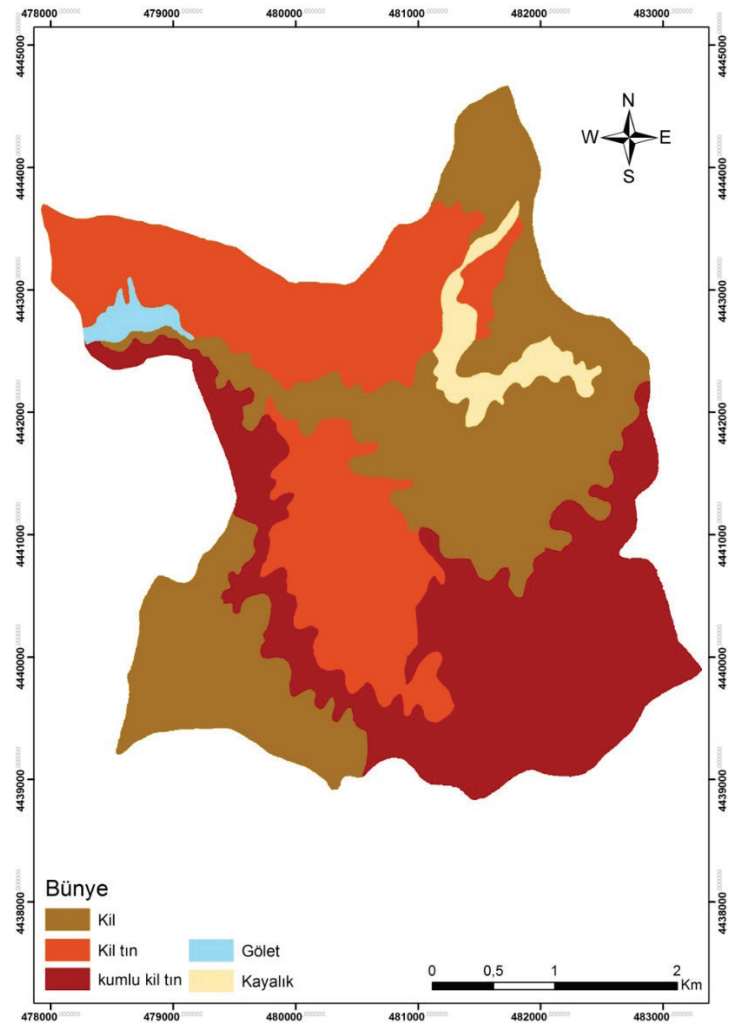

Şekil 5- Çalışma alanının bünye haritası

Figure 5-Texture map of the study area

kriterlerin ikili karşılaştırmalarına ait ortalama tutarlılık oranının ise 0.09 olduğu belirlenmiştir.

Yapılan AHS analizi sonucu kriterlerin ağırlıklandırmasında eğimin en yüksek değeri almasının önemli nedeni, şüphesiz ki toprak erozyonunun oluşmasında önemli belirleyicilerden biri olmasıdır. Özellikle toprak yüzeyinde herhangi bir koruyucu örtü bulunmaması durumunda, eğim artışına bağlı olarak yüzey akışı, dolayısıyla toprak taşınımında artış meydana gelmektedir (Dengiz \& Akgül 2005). Bu nedenle toprak-su muhafazas1 tedbirleri alınmadan veya çok az tedbirler alınarak işlemeli tarımın yapılabilmesi için kritik eğim olan \% 10-12'yi geçmemesi gerekmektedir (Sönmez 1994). 


\section{Çizelge 5- Seçilen alt faktörlerin Z-Skor değerleri}

Table 5-Z-Score map of the selected subfactors

\begin{tabular}{|c|c|c|c|c|c|c|c|c|}
\hline \multirow{2}{*}{$\begin{array}{l}\text { Arazi kullanım } \\
\text { Sinıf } \\
\end{array}$} & \multicolumn{3}{|c|}{ Ĕgim } & \multicolumn{2}{|l|}{ Erozivite } & \multicolumn{3}{|l|}{ Bünye } \\
\hline & Z-Skor değeri & Sinlf $(\%)$ & Z-Skor değeri & Sinlf & Z-Skor değeri & \multicolumn{2}{|l|}{ Sinıf } & Z-Skor değeri \\
\hline Kuru tarım & -1.1554 & $0-7$ & 1.1619 & $<60$ & 1.3805 & \multicolumn{2}{|l|}{ Kil } & -1.1619 \\
\hline Mera & 0.6419 & $7-13$ & 0.3873 & $60-90$ & 0.6135 & \multicolumn{2}{|c|}{ Kil-tın } & 1.1619 \\
\hline Meyve ve fundalık & -0.2567 & $13-20$ & -0.3873 & $90-120$ & -0.1533 & \multicolumn{2}{|c|}{ Kumlu-kil Tin } & 0.3873 \\
\hline Zayıf mera & -0.2567 & $20+$ & -1.1619 & $120-160$ & -0.9203 & & & \\
\hline Zayıf orman & 0.6419 & & & $>160$ & -0.9203 & & & \\
\hline Su yüzeyi & 1.5406 & & & & & & & \\
\hline Çıplak kaya & -1.1554 & & & & & & & \\
\hline $\begin{array}{l}\text { Yükseklik } \\
\text { Sinıf }(m)\end{array}$ & Z-Skor değeri & & $\begin{array}{l}\text { Toprak derinliği } \\
\text { Sinıf }(\mathrm{cm})\end{array}$ & & Z-Skor değeri & $\begin{array}{l}\text { Bitki yoğunluğu } \\
\text { Sinıf (\%) }\end{array}$ & \multicolumn{2}{|c|}{ Z-Skor değeri } \\
\hline $1340-1440$ & 1.1619 & & Derin $-0.3873(90$ & & 1.1619 & $0-50$ & \multicolumn{2}{|c|}{-10910} \\
\hline $1240-1340$ & 0.3873 & & Orta derin $(90-50)$ & & 0.3873 & \multirow{2}{*}{$50-70$} & \multirow{2}{*}{\multicolumn{2}{|c|}{$\begin{array}{l}-1.0910 \\
0.2182\end{array}$}} \\
\hline $1140-1240$ & -0.3873 & & $\operatorname{Siğ}(50-20)$ & & -0.3873 & & & \\
\hline $1040-1140$ & -1.1619 & & Çok sığ $(20-0)$ & & -1.1619 & $70-$ & \multicolumn{2}{|c|}{0.8728} \\
\hline
\end{tabular}

Çizelge 6- Parametrelere ait ağırlık değerlerinin belirlenmesine yönelik AHS tekniği hesaplamaları Table 6-Calculations of AHS technique to determine weighted values for parameters

\begin{tabular}{|c|c|c|c|c|c|c|c|}
\hline \multicolumn{8}{|c|}{ İkili karşılaştırmalar matrisi } \\
\hline & $\begin{array}{l}\text { Eğim } \\
(\%)\end{array}$ & $\begin{array}{l}\text { Bünye } \\
(\%)\end{array}$ & $\begin{array}{l}\text { Arazi } \\
\text { kullanım }\end{array}$ & $\begin{array}{l}\text { Yăgls } \\
(\mathrm{mm})\end{array}$ & $\begin{array}{l}\text { Yükseklik } \\
(\mathrm{m})\end{array}$ & $\begin{array}{l}\text { Toprak derinliği } \\
(\mathrm{cm})\end{array}$ & $\begin{array}{l}\text { Bitki örtüsü } \\
(\%)\end{array}$ \\
\hline Eğim (\%) & 1.000 & 4.000 & 6.000 & 7.000 & 2.000 & 3.000 & 7.000 \\
\hline Bünye (\%) & 0.250 & 1.000 & 2.000 & 3.000 & 2.000 & 5.000 & 2.000 \\
\hline Arazi kullanım & 0.166 & 0.500 & 1.000 & 7.000 & 2.000 & 5.000 & 7.000 \\
\hline Yağış (mm) & 0.142 & 0.333 & 0.142 & 1.000 & 2.000 & 5.000 & 7.000 \\
\hline Yükseklik (m) & 0.500 & 0.500 & 0.500 & 0.500 & 1.000 & 3.000 & 2.000 \\
\hline Toprak derinliği (cm) & 0.333 & 0.200 & 0.200 & 0.200 & 0.333 & 1.000 & 5.000 \\
\hline Bitki örtüsü (\%) & 0.142 & 0.500 & 0.142 & 0.142 & 0.500 & 0.200 & 1.000 \\
\hline Toplam & 2.5 & 7.0 & 9.9 & 18.8 & 9.8 & 22.2 & 31 \\
\hline \multicolumn{8}{|c|}{ Normalize edilmiş ikili karşılaştırmalar matrisi } \\
\hline & $\begin{array}{l}\text { Ĕgim } \\
(\%)\end{array}$ & $\begin{array}{l}\text { Bünye } \\
(\%)\end{array}$ & $\begin{array}{l}\text { Arazi } \\
\text { kullanım }\end{array}$ & $\begin{array}{l}Y a g_{l} l s \\
(\mathrm{~mm})\end{array}$ & $\begin{array}{l}\text { Yükseklik } \\
(\mathrm{m})\end{array}$ & $\begin{array}{l}\text { Toprak derinliği } \\
(\mathrm{cm})\end{array}$ & $\begin{array}{l}\text { Bitki örtüsü } \\
(\%)\end{array}$ \\
\hline Eğim (\%) & 0.400 & 0.570 & 0.606 & 0.372 & 0.204 & 0.135 & 0.222 \\
\hline Bünye (\%) & 0.100 & 0.142 & 0.202 & 0.159 & 0.204 & 0.222 & 0.060 \\
\hline Arazi kullanım & 0.060 & 0.071 & 0.101 & 0.372 & 0.204 & 0.222 & 0.222 \\
\hline Yağış (mm) & 0.050 & 0.047 & 0.014 & 0.053 & 0.204 & 0.222 & 0.222 \\
\hline Yükseklik (m) & 0.200 & 0.071 & 0.050 & 0.026 & 0.102 & 0.135 & 0.060 \\
\hline Toprak derinliği (cm) & 0.133 & 0.028 & 0.020 & 0.010 & 0.030 & 0.040 & 0.161 \\
\hline Bitki örtüsü (\%) & 0.050 & 0.071 & 0.014 & 0.007 & 0.051 & 0.009 & 0.032 \\
\hline \multicolumn{8}{|c|}{ Öncelik vektör } \\
\hline & \multicolumn{4}{|c|}{ Normalize edilmiş satırlar toplamı } & \multicolumn{2}{|c|}{ Normalize edilmiş satırlar ortalaması } & $\begin{array}{l}\text { Öncelik } \\
\text { vektörü }\end{array}$ \\
\hline Eğim (\%) & \multicolumn{4}{|c|}{2.509} & \multicolumn{2}{|c|}{$2.509 / 7$} & 0.358 \\
\hline Bünye (\%) & \multicolumn{4}{|c|}{1.089} & \multicolumn{2}{|c|}{$1.089 / 7$} & 0.156 \\
\hline Arazi kullanım & \multicolumn{4}{|c|}{1.252} & \multicolumn{2}{|c|}{$1.252 / 7$} & 0.179 \\
\hline Yağ1ş (mm) & \multicolumn{4}{|c|}{0.812} & \multicolumn{2}{|c|}{$0.812 / 7$} & 0.116 \\
\hline Yükseklik (m) & \multicolumn{4}{|c|}{0.644} & \multicolumn{2}{|c|}{$0.644 / 7$} & 0.092 \\
\hline Toprak derinliği (cm) & \multicolumn{4}{|c|}{0.422} & \multicolumn{2}{|c|}{$0.422 / 7$} & 0.060 \\
\hline Bitki örtüsü (\%) & \multicolumn{4}{|c|}{0.234} & \multicolumn{2}{|c|}{$0.234 / 7$} & 0.033 \\
\hline \multicolumn{7}{|c|}{ Maksimum özdeğer $(\lambda)_{\max }=7.8$, Tutarlılık indeksi $(\mathrm{TI})=0.13$, Tutarlılık oranı $(\mathrm{TO})=0.09$} & \\
\hline
\end{tabular}


Eğimin hemen ardından ikinci en yüksek ağırlık değerini arazi kullanımının alınması da yaklaşımın doğruluğunu göstermektedir. Çünkü doğal süreçler içerisinde genellikle yüksek eğimli arazilerden taban arazilere sürekli toprak taşınımının meydana gelmesi olağan bir işlem olarak görülmekte ve toprak oluşum süreci içerisinde telafi olabilmektedir. Fakat günümüzde toprak erozyonu ve arazi bozulumu kavramı özellikle arazilerin plansız, amaç dışı ve yanlış kullanımlarından dolayı oluşmaktadır.

Doğrusal kombinasyon tekniği dikkate alınarak oluşturulan çalışma alanına ait erozyon risk haritası Şekil 6' da ve her bir erozyon risk sınıflarının alansal ve oransal dağılımları ise Çizelge 7'de verilmiştir.

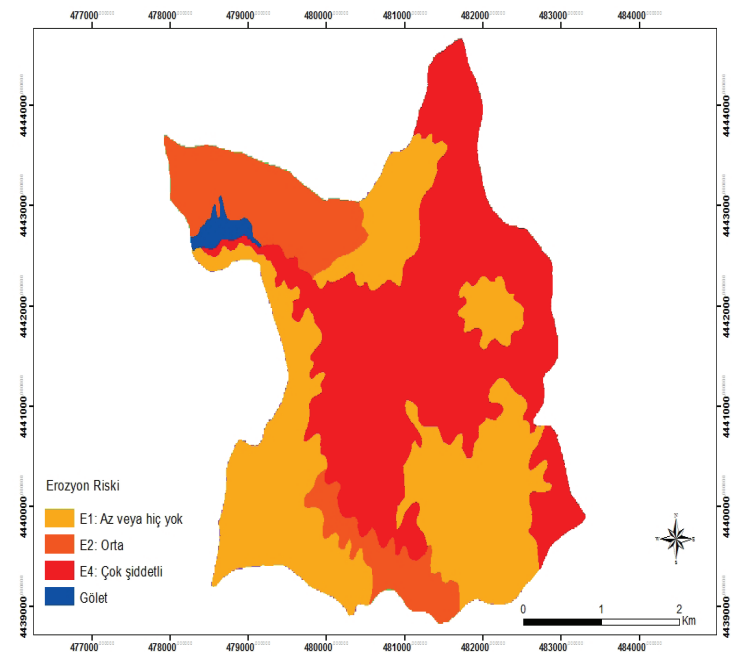

Şekil 6- Çalışma alanının erozyon risk haritası

Figure 6- Erosion risk map of the study area

\section{Çizelge 7- Erozyon risk sınıflarının alansal ve oransal dağılımı}

Table 7- Spatial and proportional distribution of erosion risk classes

\begin{tabular}{lll}
\hline Erozyon risk sinifi & Alan $(\mathrm{ha})$ & Oran $(\%)$ \\
\hline E1 & 650 & 37.5 \\
E2 & 259 & 15.0 \\
E4 & 795 & 45.9 \\
Gölet & 28 & 1.6 \\
Toplam & 1732 & 100 \\
\hline
\end{tabular}

Buna göre havzanın yaklaşık \% 45.9'u çok şiddetli erozyon riski ile karşı karşıya kalırken alanın \% 37.5'inde ise erozyon riski bulunmadığ 1 belirlenmiştir. Aynı havzada Dengiz et al (2009) farklı modelsel yaklaşımla yaptıkları erozyon risk çalışmasında, alanın \% 44.4'ünün yüksek erozyonun riski altında olduğunu buna karşın toplam havzanın \% 42.0'sinin ise çok az risk taşıdı̆̆ını veya hiç risk taşımadığını belirlemişlerdir. Çalışmaların sonuçları karşılaştırıldığında, birbirleri ile oldukça yakın paralellik gösterdiği görülmektedir.

Havzada erozyon riskinin yüksek olduğu yerler, eğimi fazla yamaç araziler üzerinde ve koruyucu bir bitki örtüsünün olmadığı veya çok zayıf olduğu, hatta yer yer kuru tarım olarak kullanılan alanlar olduğu belirlenmiştir.

\section{Sonuçlar}

$\mathrm{Bu}$ çalışma ile Güvenç Havzası'nda erozyona etki eden parametrelerin değerlendirilmesinde çok kriterli karar verme yöntemlerinden biri olan AHS ve doğrusal kombinasyon tekniğinden yararlanılmıştır. Yapılan çalışma sonucunda; havzanın \% 45.9'unun şiddetli ve çok şiddetli erozyon riski altında olduğu, alanın $\% 15$ 'inin orta düzeyde ve $\% 37.5$ 'inin ise erozyon tehlikesine yönelik risk taşımadığı belirlenmiştir. Şiddetli erozyon riski altında olan alanlar genellikle eğimi yüksek, sığ toprak derinliğine sahip, bitki örtüsünce zayıf ve özelikle yer yer kuru tarım olarak kullanılan alanlardır. Buna karşılık erozyon riski çok az veya hiç olmayan alanları ise genellikle yüksek düzlük araziler ile havzanın kot seviyesi en düşük yeri olan gölet etrafinda yer alan, hafif eğimli bitki örtüsünce kaplı alanlar oluşturmaktadır.

Bu çalışma UA, CBS, AHS ve Z-Skor teknikleri tarafindan erozyon risk durumunun ortaya konulabileceğini göstermektedir. Bu yaklaşımla nicel olarak bir alanda erozyon tehlikesi belirlenmiştir. Elde edilen sonuçlar farklı yeni bilimsel çalışmalara ve yerel yöneticilere bilimsel veri sağlayacaktır. Modelden elde edilen sonuçlara göre, çalışma alanının geniş alanlarda şiddetli erozyon tehlikesi ile karşı karşıya olduğu belirlenmiştir. Böylece 
şiddetli erozyon alanları, acil müdahale gerektiren yerler olarak belirlenmiştir. Diğer alanların ise acil koruma çalışmalarına öncelik verilmelidir.

Havzada özellikle eğimin fazla olması nedeniyle, erozyona en fazla etki eden faktör eğim olarak belirlenmiştir. Etkili olan diğer önemli faktörler ise arazi kullanımı/arazi örtüsü, toprak tekstürü, yağış, yükseklik, toprak derinliği ve bitki örtüsü olmuştur. Erozyona hassas olan alanlarda bu faktörlerin de göz önünde bulundurularak toprakların taşınımını engelleyici tedbirlerin alınması gerekmektedir.

CBS ve UA teknikleri, yeni yöntem ve modellerle gün geçtikçe artan bir öneme sahip olmuştur. Erozyona etki eden faktörlerin çoğunda CBS ve UA tekniklerinin kullanılması, analizlerin yapılmasında ve haritaların oluşturulmasında kolaylıklar sağlamıştır. Bu tekniğin kullanılması verilere daha kısa sürede ulaşılmasına, analiz ve sorgulama işlemi ile haritaların üretilmesine olanak tanımıştır. $\mathrm{Bu}$ tekniklerin kullanımlarının yaygın hale getirilmesi, yerel yöneticilerin ve bilim adamlarının daha hızlı ve doğru olarak sonuçlara ulaşmasına imkân sağlayacaktır.

\section{Kaynaklar}

Carver S J (1991). Integrating multi-criteria evaluation with geographical information systems. International Journal of Geographical Information Systems 5(3): 321-339

CORINE (1992). Commission of the European Communities. Soil Erosion Risk and Important Land Resources, Luxembourg

Dengiz O \& Başkan O (2005). Ankara Güvenç Havzası temel toprak özellikleri ve sinıflandırılması. Selçuk Üniversitesi Ziraat Fakültesi Dergisi 19(37): 27-36

Dengiz O \& Akgül S (2005). Soil erosion risk assessment of the Gölbaşı Environmental Protection Area and its vicinity using CORINE Model. Turkish Journal of Agriculture and Forestry 29(6): 439-448

Dengiz O \& Sarığlu F E (2013). Parametric approach with linear combination technique in land evaluation studies. Tarm Bilimleri Dergisi-Journal of Agricultural Sciences 19(2): 101-112

Dengiz O, Yakupoğlu T \& Baskan O (2009). Soil erosion assessment using geographical information system
(GIS) and remote sensing (RS) study from AnkaraGuvenc Basin, Turkey. Journal of Environmental Biology 30(3): 339-344

DSİ (1969). Türkiye Hidroloji Haritası. Enerji ve Tabi Kaynaklar Bakanlığı DSİ. Yeraltı Suları Daire Başkanlığı, Ankara

Flanagan D C \& Nearing M A (1995). USDA-Water erosion prediction project: hillslope and watershed model documentation. NSERL Report No. 10. West Lafayette Ind. USDA-ARS National Soil Erosion Research Laboratory

ICONA (1997). Guidelines for Mapping and Measurement of Rainfall Induced Erosion Processes in the Mediterranean Coastal Areas. Priority Action Program Regional Activity Centre. Split, Croatia

Kumar N V \& Ganesh L S (1996). A simulation-based evaluation of the approximate and exact Eigenvector Methods employed in AHP. European Journal of Operational Research 95(3): 656-662

Lal R (2001). Soil degradation by erosion. Land Degradation \& Development 12: 519-539

Malczewski J (1996). A GIS-based approach to multiple criteria group decision-making. Geographical Information Systems 10(8): 955-971

Manrique L A (1988). LEAM: Land Erodibility Assessment Methodology. Edit. \& Pub. Shop, Honolulu, HI

MGM (2013). Devlet Meteoroloji İşleri Genel Müdürlüğü Ankara İstasyonu 1970-2013 Dönemi Ortalama ve Ekstremler Klimatoloji Bülten, Ankara

Morgan R P C, Quinton J N \& Rickson J R J (1992). Soil erosion prediction model for the Europian Community. GB-ISCO-WASWC

MTA (1994). Maden Tetkik Arama Genel Müdürlüğü, Ankara

Patrono A (1998). Multi-Criteria Analysis and Geographic Information Systems: Analysis of Natural Areas and Ecological Distributions. Multicriteria Analysis for Land-Use Management, In: Euro Beinat and Peter Nijkamp, Kluwer Academic Publishers (Eds), Environment and Management, AA Dordrecht, The Netherlands, pp. 271-292

Renard K G, Foster G R, Weesies G A \& Porter J P (1991). RUSLE, revised universal soil loss equation. Journal of Soil Water Conservation 46(1): 30-33

Saaty T L (1980). The Analytic Hierarchy Process. McGraw-Hill, New York 
Sönmez K (1994). Toprak Koruma. Atatürk Üniversitesi Ziraat Fakültesi Yayınları No: 169, Erzurum

TÜGEM (2008). T. C. Tarım ve Köyişleri Bakanlığı, Tarımsal Üretim ve Geliştirme Genel Müdürlüğü, Toprak ve Arazi Sınıflaması Standartları Teknik Talimatı ve İlgili Mevzuat. Ankara, s. 184

Van Zuidam R A (1986). Aerial photo-interpretation in terrain analysis and geomorphologic mapping. Smits Publishers, The Netherlands, pp. 442

Williams J R, Jones C A \& Dyke P T (1990). The EPIC model. United States Department of Agriculture (USDA) Technical Bulletin No: 1768
Wischmeier W H \& Smith D D (1978). Predicting rainfall erosion losses: a guide to conservation planning. Agricultural Handbook No: 537. United States Department of Agricultural Science and Education Administration, Agricultural Research, Washington, DC. s. 58

Wu Q \& Wang M (2007). A framework for risk assessment on soil erosion by water using an integrated and systematic approach. Journal of Hydrology 337(1-2): 11- 21

Zhang R, Liu X, Heathman G C, Yao X, Hu X \& Zhang G (2013). Assessment of soil erosion sensitivity and analysis of sensitivity factors in the Tongbai-Dabie mountainous area of China. Catena 101: 92-98 